\title{
O ESPAÇO LIVRE CORPORATIVO EM SÃO PAULO - O CONCEITO DE ESPAÇO LIVRE PARTICULAR DE USO PÚBLICO
}

\author{
CORPORATE OPEN SPACES IN SÃO PAULO - THE CONCEPT OF PRIVATELY OWNED PUBLIC \\ OPEN SPACE
}

\section{HEPNER, Alexandre}

Aluno de graduação da Faculdade de Arquitetura e Urbanismo da FAUUSP e pesquisador do Projeto Quapá, com bolsa de iniciação científica pela Fapesp.

E-mail: hepnerz@yahoo.com.br

\section{RESUMO}

Este artigo consiste numa breve apresentação de uma pesquisa que vem sendo realizada há cerca de três anos junto ao Projeto Quapá sobre as características espaciais, morfológicas e de desenho urbano das centralidades corporativas em São Paulo. Partindo de uma discussão em torno da apropriação pública do espaço privado e das relações entre as grandes empresas, o mercado imobiliário e o poder público, este trabalho tem por objetivo identificar as vertentes contemporâneas da produção paisagística corporativa através do estudo dos projetos mais significativos que compõem os sistemas de espaços livres dos centros empresariais da metrópole.

\section{Palavras-chave: Paisagismo, arquitetura corporativa, praça corporativa.}

\section{ABSTRACT}

This paper consists in a brief presentation of a research that has been undertaken for around three years in association with the Quapá Project about the morphology, urban design and space characteristics of corporate centralities in São Paulo. Starting from a discussion about the public appropriation of private space and the relationship between large business companies, the real state market and the public administration, this work aims to analyze the contemporary corporate landscape architecture through the study of the most significant projects that compose the business centers of the metropolis.

Key words: Landscape architecture, corporate architecture, corporate plaza.

\section{Introdução}

Numa cidade, desenvolvem-se atividades dos mais diferentes tipos, englobando a enorme diversidade de aspectos que compõem a vida cotidiana do cidadão que ali habita, dentre os quais o trabalho, a habitação, o lazer, as manifestações culturais, entre muitos outros. Algumas destas atividades, de acordo com sua importância social, cultural, política ou econômica, vêm a adquirir maior ou menor destaque: enquanto algumas envolvem um número pequeno de pessoas e se desenrolam despercebidamente, outras envolvem contingentes numerosos e têm repercussões significativas para boa parte da população.

Desta maneira são estabelecidas relações hierárquicas entre as diferentes atividades, de forma a compor uma rede que aumenta em complexidade conforme também aumenta o tamanho da cidade nas quais estão inseridas. Numa metrópole com as dimensões de São Paulo, nas quais são realizadas atividades de âmbito não apenas urbano, mas também regional, nacional e até mesmo global, esta rede pode adquirir proporções incomensuráveis.

Como cada atividade ocupa um espaço específico dentro da cidade, estes espaços acabam sendo caracterizados pela sua função, traduzindo espacialmente esta rede de relações hierárquicas. 
Por conseguinte, no contexto de qualquer cidade, há uma diferenciação de valores entre os seus espaços: alguns assumem um maior valor simbólico, seja por possuírem alguma importância de caráter histórico, constituírem alguma espécie de marco, por concentrarem alguma função específica, ou por estarem sujeitos a alguma condição ambiental vantajosa.

É a partir deste pressuposto que se passa a reconhecer a existência da centralidade num ambiente urbano. Admitindo-se que num determinado espaço possa se desenvolver alguma atividade de maneira exclusiva, seja de caráter comercial, religioso, administrativo, ou qualquer outro, conclui-se que eventualmente este se torne destino de parte expressiva dos deslocamentos da população. Isto pode acontecer com uma grande ou pequena freqüência; por exemplo, um templo pode receber fiéis apenas anualmente, durante alguma festividade de caráter religioso, enquanto um mercado pode concentrar diariamente uma grande quantidade de visitantes. $O$ que importa é que ambos, a sua maneira, representam uma centralidade porque são pontos para os quais as pessoas, eventualmente, convergem, com o intuito de realizar alguma atividade específica. A estes tipos de atividades dá-se o nome de funções centrais.

Nas grandes cidades contemporâneas, as funções centrais correspondem, em geral, ao mais expressivo grupo de atividades econômicas que compõem o sistema de produção capitalista: o setor terciário. O centro das principais metrópoles do mundo é ocupado intensamente pela presença de edifícios de escritórios, sedes de empresas e corporações, hotéis e agências do setor financeiro, e São Paulo não é uma exceção: diversos bairros da cidade estão repletos de empreendimentos do gênero, sobretudo no quadrante sudoeste, tido tradicionalmente como o reduto das elites e como a região mais valorizada e privilegiada da cidade.

Nestas centralidades em que as atividades terciárias são predominantes, a instalação densa de empreendimentos comerciais e de serviços levou à conformação de situações urbanas marcadas por características espaciais e morfológicas significativas, distintas das existentes no restante da cidade. Além disso, estruturou-se nestes locais um sistema de espaços livres bastante diferenciado, marcado pela integração entre espaços públicos e privados e pelo uso de tratamentos paisagísticos sofisticados. Estas características tornam as centralidades terciárias de São Paulo um importante objeto de estudo, o qual vem sendo, há quase três anos, alvo de uma pesquisa desenvolvida junto ao Projeto Quapá - Quadro do Paisagismo no Brasil.

\section{O espaço livre particular de uso público}

Provavelmente a principal característica espacial que difere as centralidades de São Paulo de outras regiões da metrópole é a existência significativa de espaços de transição entre os espaços públicos e privados. Muitas vezes, o transeunte comum tem dificuldade em perceber a separação entre ambos, pois em diversos empreendimentos corporativos os limites entre lote e passeio público não estão claramente demarcados por muros, grades, pisos diferenciados ou outros tipos de marcos visuais, como é comum no restante da cidade. Como resultado, também se torna turva a linha que separa o que é de propriedade privada e de propriedade pública; os dois conceitos passam a se confundir e o contraste entre ambos deixa de ser tão explícito. De quem é a propriedade destes espaços, se estão dentro de lotes privados mas qualquer um pode acessá-los? Para chegar-se a alguma conclusão sobre o assunto, torna-se necessário rever o próprio conceito de propriedade.

A Constituição Brasileira de 1988 garante aos cidadãos o direito à propriedade particular do espaço físico. Em conseqüência, todos os espaços podem ser divididos entre aqueles cuja posse é privada e aqueles de posse pública. O sistema de espaços livres públicos - que inclui as ruas, as praças, os parques, as calçadas e outros passeios públicos - pertence a toda a população, e portanto estes espaços podem ser acessados livremente por toda e qualquer pessoa, ainda que em alguns casos hajam restrições de uso estabelecidas pelas autoridades públicas, como, 
por exemplo, os horários de funcionamento dos parques. Em contrapartida a este direito de propriedade, toda a sociedade deve arcar, através do pagamento dos impostos, com os custos da construção e manutenção de tais espaços públicos.

Por outro lado, possuir a posse privada de algum espaço significa, de um modo genérico, que é o proprietário quem estabelece as restrições de uso e acesso, e a população é obrigada a obedecê-las, ainda que não concorde com as mesmas (obviamente, o proprietário não pode estabelecer regras que entrem em conflito com as leis de sua sociedade); em contrapartida, o proprietário é o único responsável pelo custeio da manutenção de seu próprio espaço.

Partindo-se destes dois pressupostos, teoricamente deveria ser uma tarefa bastante simples reconhecer a separação e as diferenças entre o espaço privado e o público. No entanto, a tarefa complica-se quando se percebe a existência de situações intermediárias, no caso de espaços que são de propriedade particular mas que podem ser acessados e utilizados pelo público em geral - situação na qual se encontra boa parte do espaço livre corporativo. Neste momento, muitos geralmente recorrem ao ambíguo termo "semi-público" para caracterizar este tipo de espaço. Existe, no entanto, muita controvérsia sobre a utilização desta nomenclatura: na verdade, não seriam estes espaços "semi-privados"? Qual a diferença entre as duas designações? Há quem considere como semi-públicos os espaços que são efetivamente de propriedade pública, mas que possuem restrições de uso, como parques, estações de trem e terminais de ônibus, já que estes não podem ser acessados universalmente da mesma maneira que as ruas e praças. Sob este ponto de vista, seria inadequado empregar o termo "semi-público" para tratar sobre o espaço livre corporativo. Paralelamente, o emprego da expressão "semi-privado" também pode gerar bastante polêmica: como um espaço pode ser semi-privado, se é propriedade de alguém? Ao instituir que algo é apenas "parcialmente privado", não estaria, desta forma, se infringindo o direito inalienável do proprietário à sua propriedade?

Deixando de lado esta discussão semântica, defende-se aqui a adoção, para caracterizar estas situações especiais, da expressão "espaço livre privado de uso público". Nos Estados Unidos, este conceito já foi consagrado através da expressão privately owned public open spaces e a muitas das cidades de grande porte contém em sua legislação urbana uma postura específica perante a produção deste tipo de espaço. Para compreender completamente seu significado, o mais indicado é separá-la em duas partes: "espaços livres privados" indica que o espaço é de posse privada, com todos os direitos e deveres implícitos nesta situação. $\bigcirc$ proprietário arca com os custos de manutenção, é ele quem custeia sua construção, também é ele o responsável por definir o programa e o projeto deste espaço, e este é livre para vendê-lo para outro indivíduo. Mas a segunda parte da expressão, "de uso público", significa que o proprietário abriu mão de estabelecer as "regras de uso", permitindo o uso e o acesso de toda a população, ainda que, novamente, possam ser feitas restrições, como em relação aos horários de uso. Geralmente o proprietário do espaço faz esta concessão com alguma intenção, seja de facilitar o acesso para o empreendimento, aprimorar as condições de conforto ambiental no interior de seu lote, ou valorizá-lo esteticamente e simbolicamente com algum tratamento paisagístico especial.

É nos empreendimentos comerciais e de serviços que surgem com maior freqüência os espaços livres privados de uso público, pois é principalmente nesta modalidade de empreendimento que a existência de tais espaços corresponde aos interesses do proprietário. Entre os fatores que estimulam o surgimento destes espaços, destaca-se a possibilidade de facilitar o acesso de clientes e consumidores, a valorização a imagem do estabelecimento ou da marca, e a criação de espaços de descanso e contemplação para visitantes e funcionários. E quando o projeto arquitetônico e paisagístico destes espaços é de boa qualidade, em geral também há uma meIhoria qualitativa do sistema de espaços públicos lindeiro, pois a abertura dos lotes aumenta a sensação de amplitude e permeabilidade do sistema público, além de oferecer áreas de estar adicionais e opções múltiplas de circulação à população em geral. 


\section{Espaço livre corporativo}

Apesar de o espaço livre de todos os empreendimentos do setor terciário serem relevantes para o presente estudo, os mais significativos são aqueles inseridos nos setores mais expressivos da economia, pois em geral é necessária uma grande acumulação de capital para a execução das obras de maior porte. Assim sendo, os principais exemplos de espaço livre corporativo são justamente as torres que abrigam escritórios de grandes empresas e corporações, em especial as multinacionais, e os bancos e outros negócios ligados ao setor financeiro.

Os vultuosos investimentos necessários à execução destas grandes obras, no entanto, nem sempre partem de uma única empresa ou grupo interessados na construção de sua sede. Existem também outros agentes do mercado imobiliário que realizam este tipo de empreendimento, e que subsistem da própria margem de lucro da construção e subseqüente venda ou locação do imóvel: as empresas construtoras e as incorporadoras de capital. Nestes casos, o edifício pode conter apenas uma única corporação, mas pode também ser parcelado para abrigar uma grande empresa por pavimento ou conjunto de pavimentos, como no caso de muitos centros empresariais; pode ter ainda cada pavimento dividido em conjuntos ou blocos para escritórios menores, ou mesmo consultórios médicos. Outros casos seguem uma lógica de produção similar, embora produzam resultados diferenciados, como é o caso dos shopping centers, hotéis e flats, os quais também representam importantes objetos de estudo.

A estética que define o projeto de arquitetura do edifício corporativo considera que a imagem do edifício estará intrinsecamente relacionada à imagem da corporação que nele "reside". A busca por uma imagem de grande valor simbólico - que demonstre os atributos da empresa, como, por exemplo, seu poderio financeiro, estabilidade, audácia e solidez - pode ser traduzida na arquitetura através de uma volumetria com linhas arrojadas, do tratamento com materiais que traduzam a "sensação de modernidade", e especialmente das próprias dimensões do edifício. Estes empreendimentos de grande porte muitas vezes exigem lotes amplos para sua implantação, o que conseqüentemente também resulta em espaços livres mais amplos e com tratamentos eventualmente mais sofisticados.

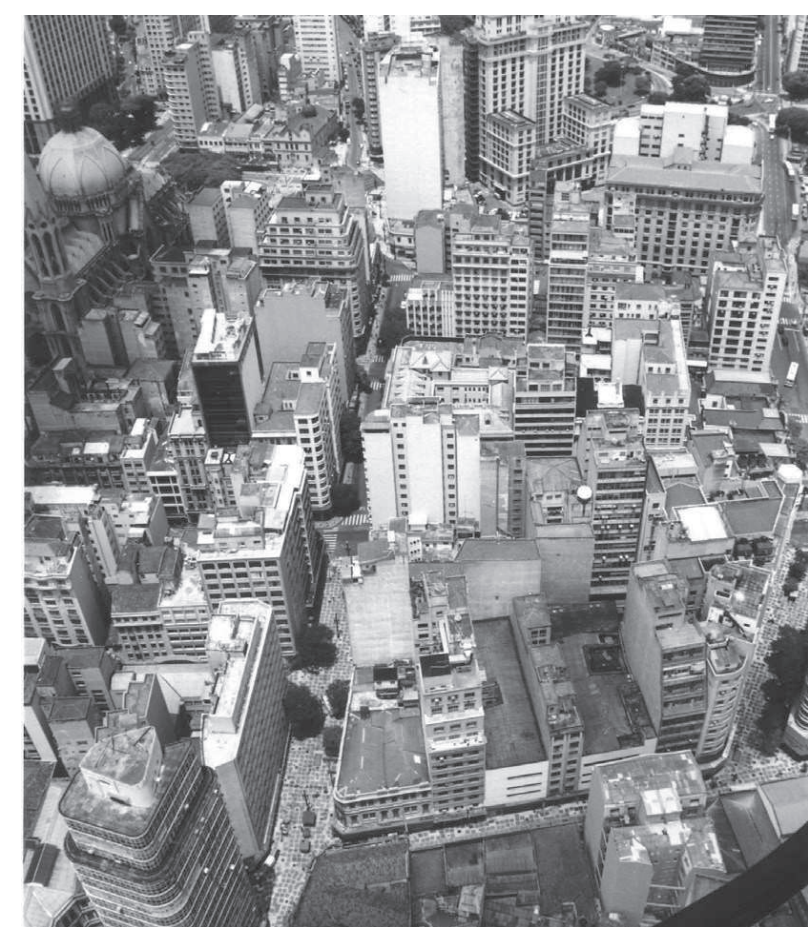

Figura 1: Centro histórico de São Paulo: ocupação em "quadras-bloco"

Crédito: Silvio Soares Macedo, 2001

\section{Espaços corporativos em São Paulo}

Diversas regiões da cidade de São Paulo abrigam hoje atividades centrais, mas nem todas estas centralidades se consolidaram concomitantemente ou de maneira semelhante. Pelo contrário, trata-se de um longo processo de expansões sucessivas da centralidade que se desenvolveu ao longo do século XX: os usos comerciais e de serviços gradativamente substituem as outras atividades que eram desenvolvidas num determinado local até tornarem-se hegemônicas; a partir daí, este espaço torna-se saturado e a centralidade é forçada a expandir-se para uma nova fronteira.

Conforme se amplia a demanda por novos espaços para as atividades comerciais, novas regiões da cidade passam por um processo de "terceirização", ou seja, de conversão numa zona em que o maior agente produtor do es- 


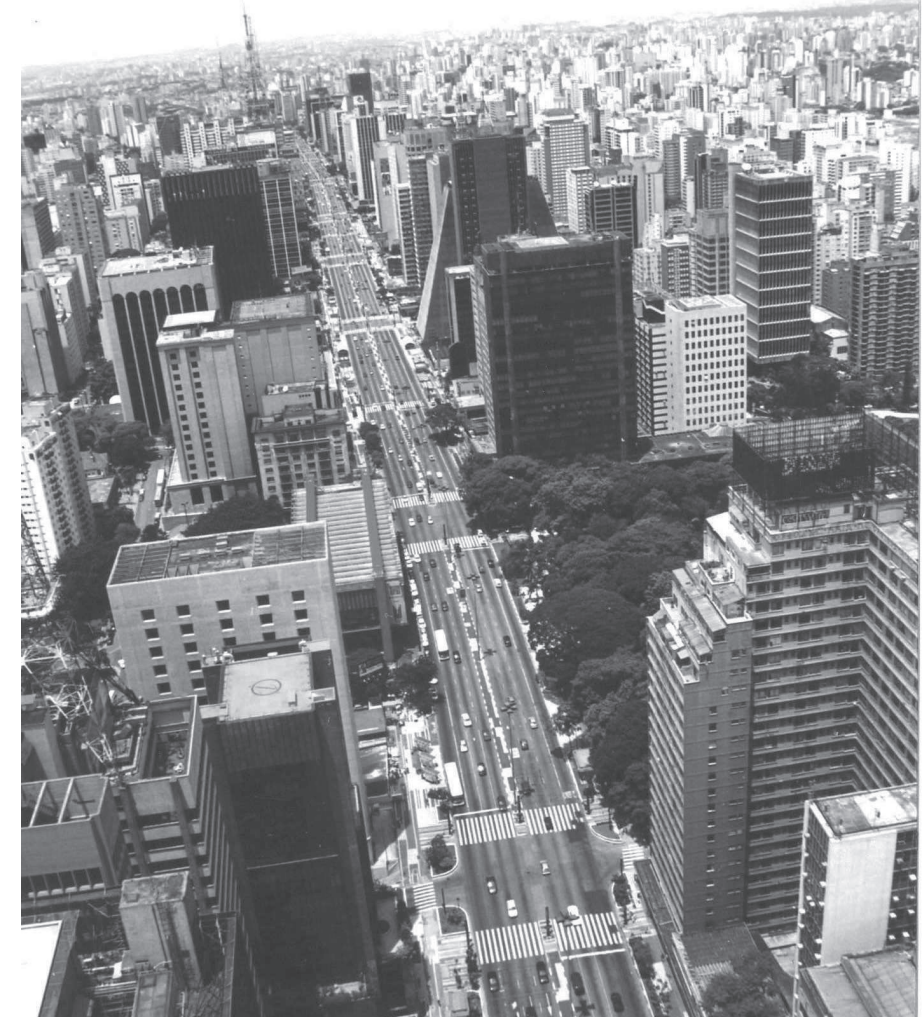

Figura 2: A avenida Paulista em sua conformação atual o centro financeiro da América Latina Crédito: Silvio Soares Macedo, 2003

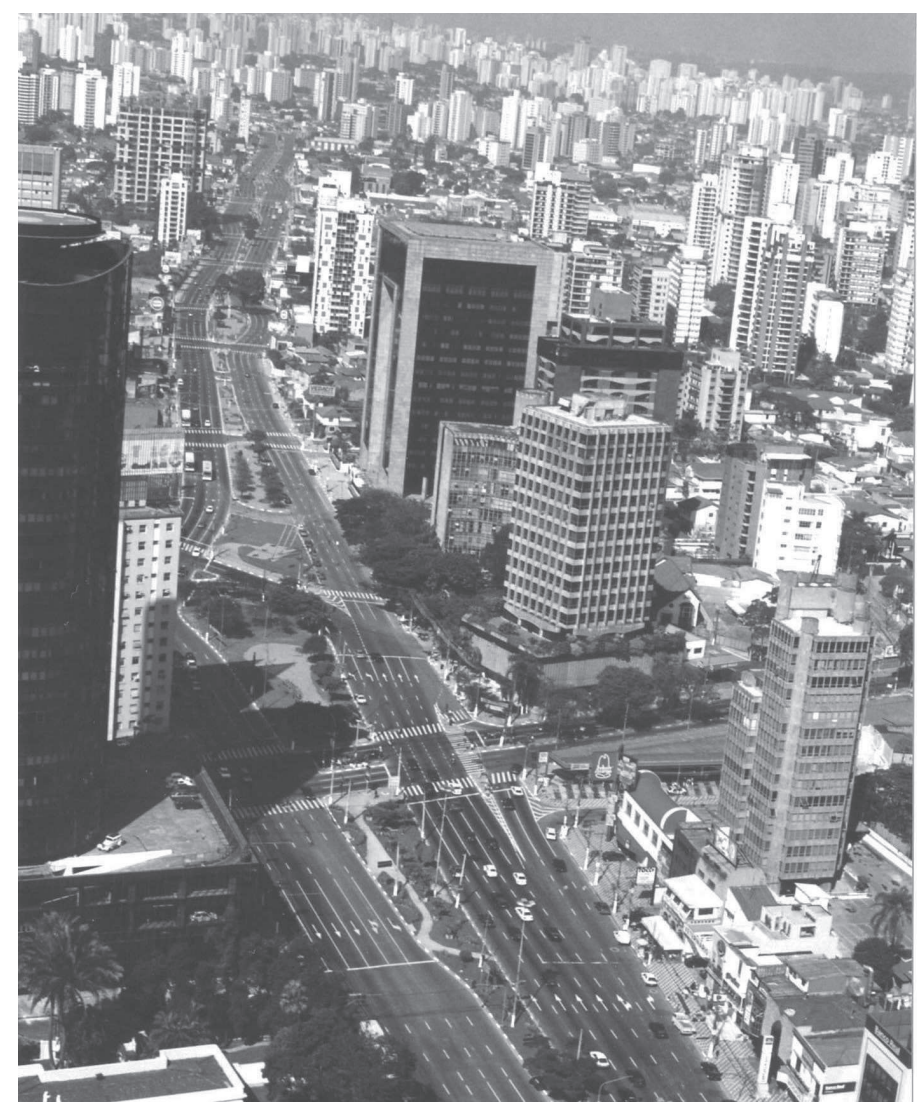

Figura 3: Avenida Brigadeiro Faria Lima Crédito: Silvio Soares Macedo, 2003 paço é o setor terciário. Antigos bairros residenciais passam, desta forma, a ser dominados por bancos e escritórios, entre outros empreendimentos do setor. Este processo pode transcorrer de diversas maneiras. Se esta transformação se der de forma não planejada, à mercê do mercado imobiliário, a tendência é produzir uma ocupação hegemônica da atividade mais lucrativa, excludente da população original, especialmente se esta for de camadas de baixa renda. A ausência de limitações suficientemente restritivas de taxas de ocupação e coeficientes de aproveitamento pode permitir um adensamento excessivo, do qual podem decorrer a saturação da infra-estrutura do bairro, em especial a viária, e a fragmentação do sistema de espaços livres. Por outro lado, a valorização imobiliária pode se traduzir em grandes melhorias para a região. Tudo isto depende da amplitude e de como se dá a intervenção da administração pública na consolidação destas áreas. As características espaciais e morfológicas de um trecho urbano específico estão, portanto, intrinsecamente relacionadas ao contexto da época em que estes espaços se consolidaram, especialmente no que diz respeito às atuações do mercado imobiliário e da administração pública na produção do espaço urbano.

Em São Paulo, este processo de expansão da centralidade iniciou-se na década de 1950, conforme as atividades terciárias passavam a se tornar hegemônicas no antigo centro histórico. Neste momento, com a degradação do centro provocada pela saturação das atividades comerciais, a centralidade paulistana começou a expandirse gradativamente para novas fronteiras, seguindo majoritariamente em direção ao rio Pinheiros ao longo do chamado "vetor sudoeste". Este fenômeno, que já foi discutido por autores como Flávio Villaça' e Heitor Frúgoli², constitui uma das bases da presente pesquisa, pois em cada uma de suas fases é possível se reconhecer uma distinta tipologia predominante para os edifícios corporativos que por sua vez 


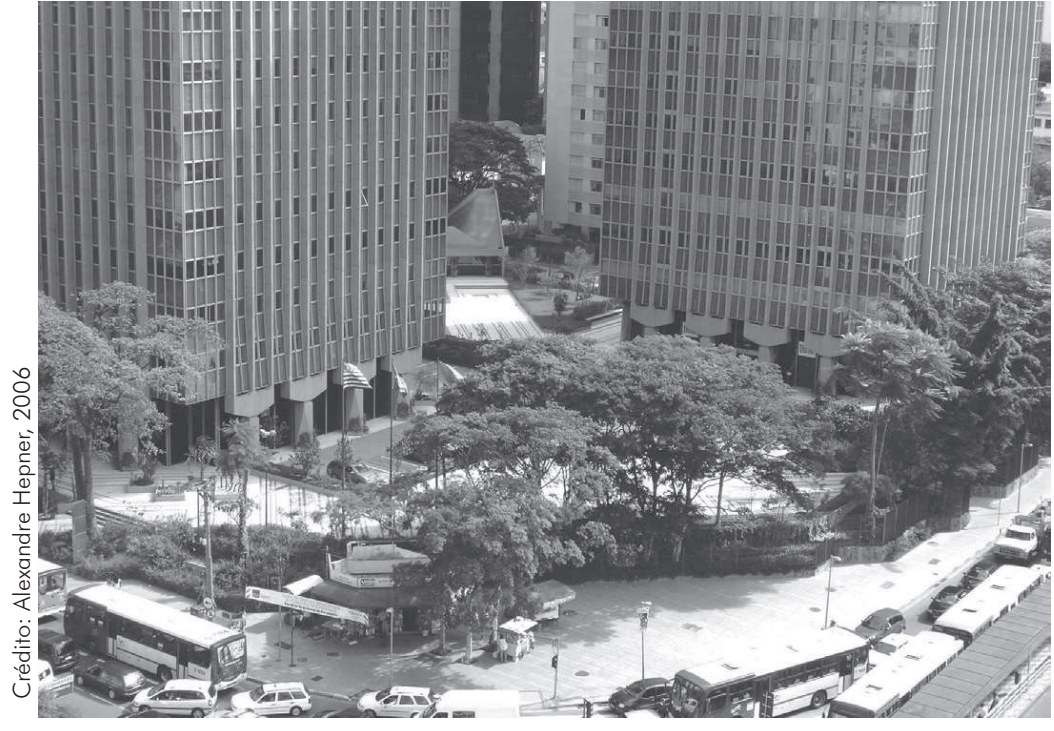

Figura 4: Brasilinvest Plaza, projeto de Ayako Nishikawa na confluência das avenidas Rebouças e Brig. Faria Lima

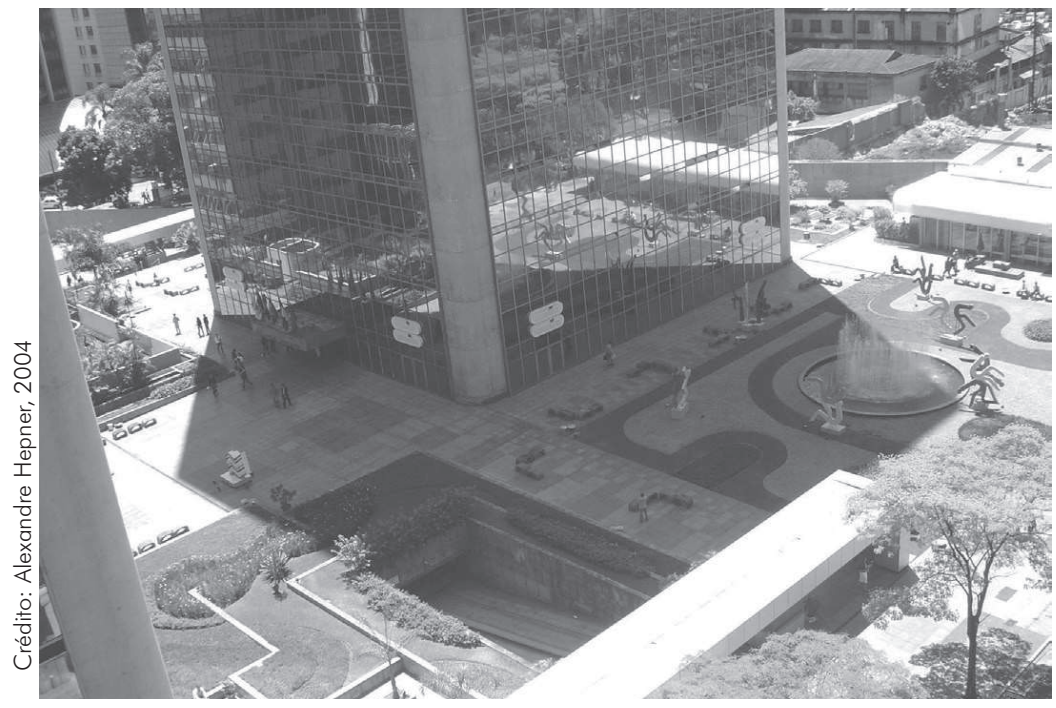

Figura 5: Cetenco Plaza, projeto paisagístico de Luciano Fiaschi na avenida Paulista: uma das praças corporativas mais conhecidas da cidade

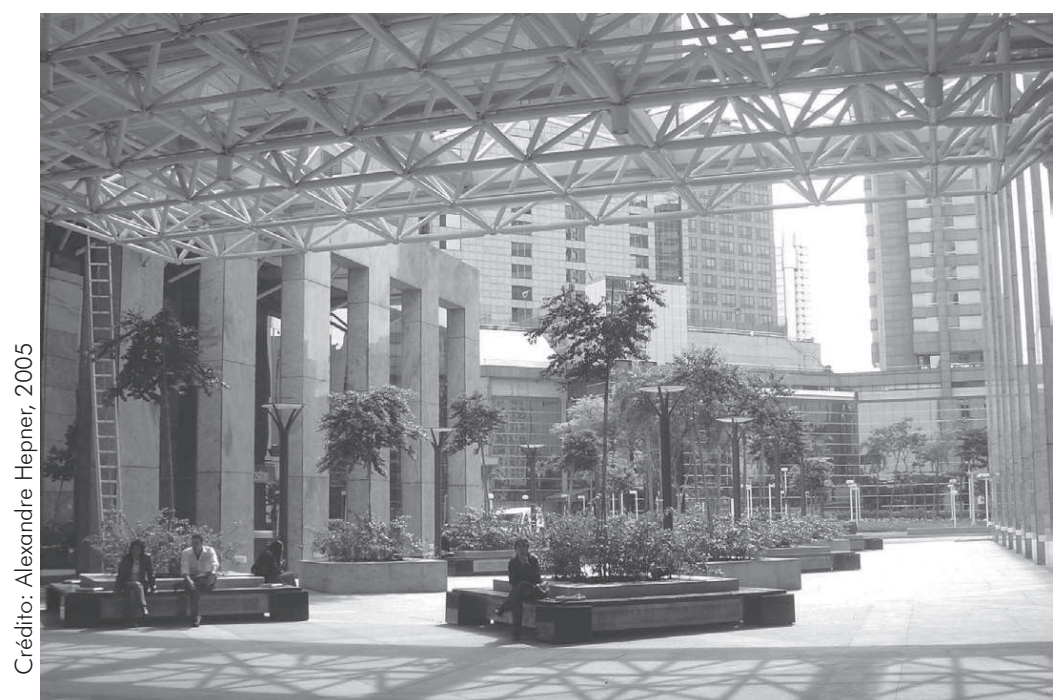

Figura 6: Praça corporativa articulando as três torres e o shopping center do Centro Empresarial Nações Unidas, na Marginal do Pinheiros, com projeto paisagístico do escritório DW/Santana resultam em sistemas de espaços livres diferentes.

Até o final da primeira metade do século passado, a tipologia que se consagrou no centro histórico é a típica da "verticalização européia", na qual os edifícios ocupam toda a extensão do lote, conformando as "quadras-bloco" (Figura 1), dentro das quais inexistem espaços livres (com exceção dos exíguos fossos de ventilação). Esta forma de ocupação específica, em que as quadras são completamente edificadas, teria se consagrado no Centro não apenas porque era de interesse do mercado imobiliário, mas também justamente por que era exigida pela legislação urbana vigente na época.

Espaços livres corporativos significativos apenas viriam a surgir durante a década de 1960, quando começaram a se instalar na avenida Paulista edifícios-sede de grandes bancos e empresas ligadas ao setor financeiro (Figura 2). Neste período, devido à nova legislação que exigia a existência de recuos pré-determinados para garantir a iluminação e ventilação entre os edifícios, consolidou-se a forma de ocupação do lote que até hoje é a mais freqüente em São Paulo: a do edifício isolado no centro do lote, cercado por estreitas faixas de recuo. Este modelo, contudo, propiciou também o surgimento no interior dos lotes de espaços livres fragmentados, desconectados do amplo sistema espacial urbano.

A próxima vertente de expansão da centralidade se dá na década de 1970 com a avenida Brigadeiro Faria Lima. Porém, o caráter dos espaços livres corporativos ali instalados se diferencia dos anteriores devido às restrições de aproveitamento do 


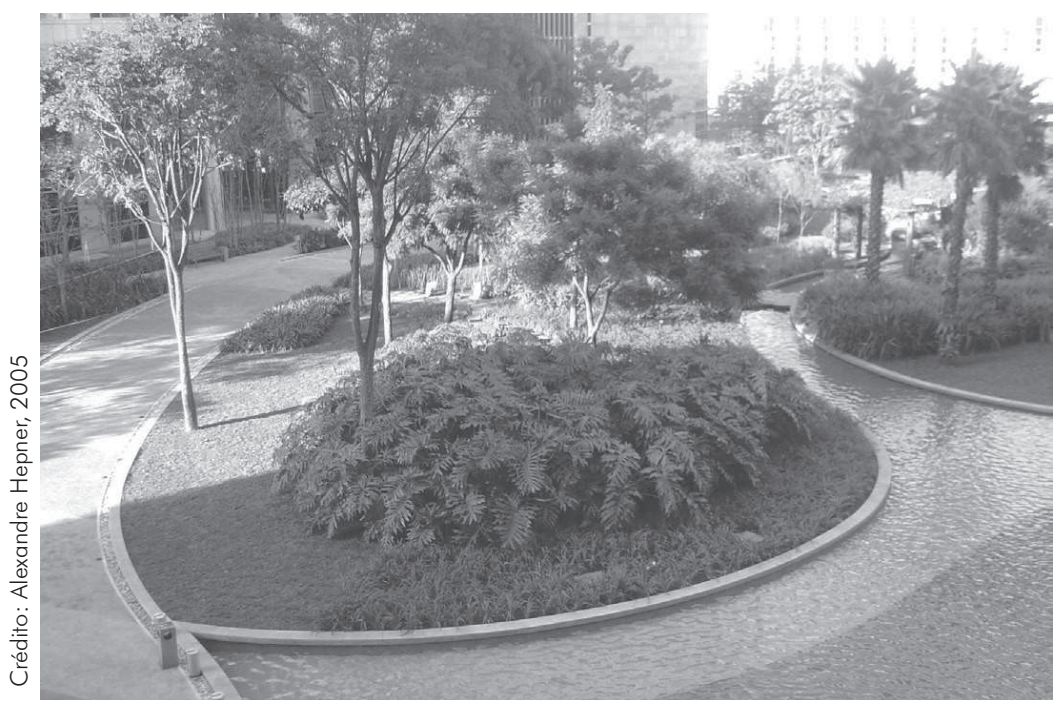

Figura 7: Jardim da sede do Bank Boston, na Marginal do Pinheiros, elaborado por Isabel Duprat: o projeto incorpora influências do paisagismo de Burle Marx Crédito: Alexandre Hepner, pner, 2005

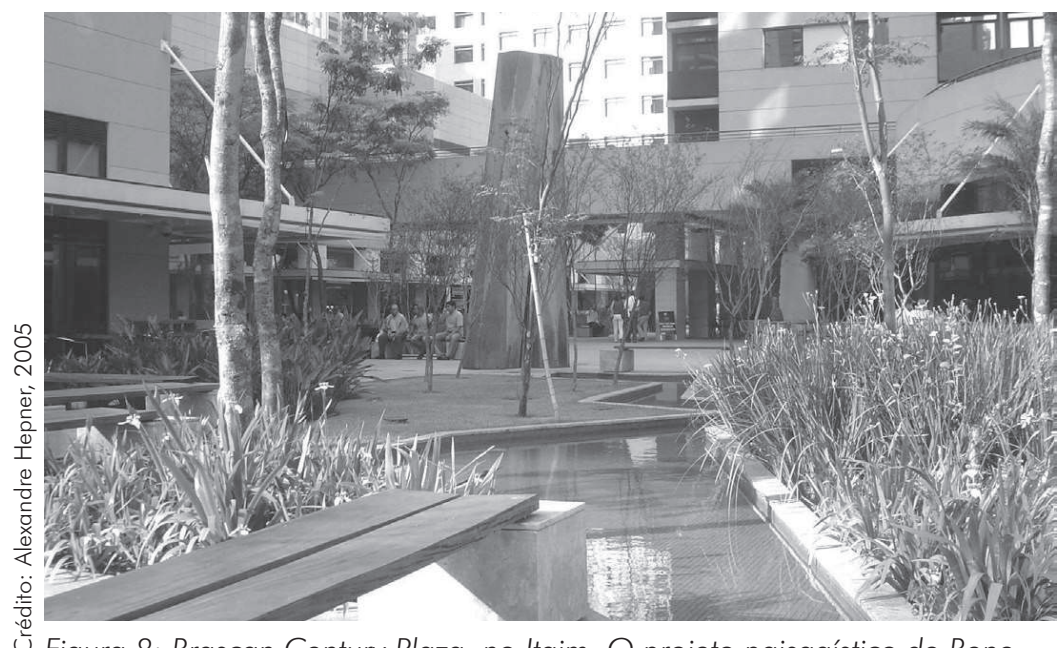

¿ Figura 8: Brascan Century Plaza, no Itaim. O projeto paisagístico de Benedito Abbud representa um novo conceito de praça corporativa: o open mall, um shopping center a céu aberto Crédito: Alexandre Hepner, 2005

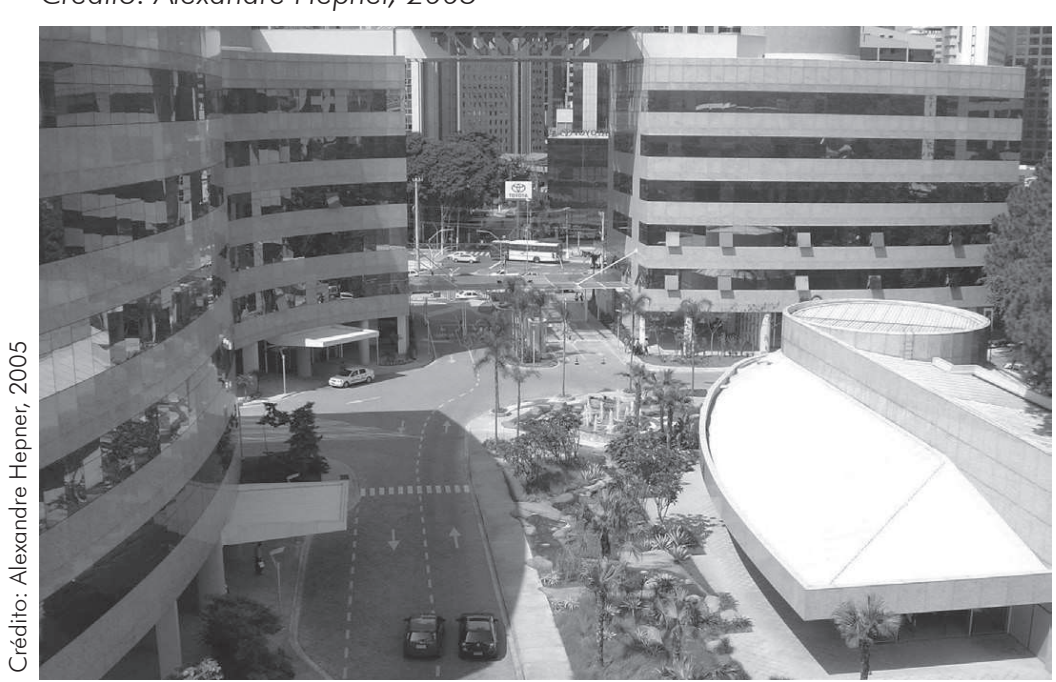

Figura 9: Millenium Office Park, na Villa Olímpia: condomínio corporativo fechado composto por quatro torres de escritórios e um centro de convenções

Fonte: Alexandre Hepner, 2005 solo construído impostas pela nova Lei de Zoneamento instituída em 1972, que garantiu a existência de espaços livres mais amplos com a adoção de taxas de ocupação e coeficientes de aproveitamento máximos muito mais restritivos que outrora (Figura 3).

A partir do final de década de 1980 , acentuou-se a chegada ao Brasil de muitas das maiores empresas multinacionais, que demandavam para sua instalação empreendimentos de grande porte. As grandes torres corporativas passaram a ser implantadas em lotes de amplas dimensões, cujos espaços livres recebiam tratamentos paisagísticos cada vez mais sofisticados, como forma de valorizar a imagem das empresas ali instaladas. A expressão máxima desta tendência são as praças corporativas, grandes espaços livres de uso público inseridos dentro de lotes particulares, que na maioria dos casos estruturam o acesso a um conjunto de torres corporativas. Estes espaços geralmente adquirem grande valor simbólico, muitas vezes equiparável ou até superior ao da imagem das fachadas do edifício corporativo, pois se abrem para utilização por (teoricamente) todas as camadas da sociedade. Além disso, por ser interesse direto de seus proprietários o investimento na manutenção constante, muitas vezes encontram-se em condições de uso muito melhores do que os espaços públicos lindeiros. Ou seja, o capital privado, por assegurar a qualidade perene destes espaços, acaba conseqüentemente the conferindo uma posição privilegiada na hierarquia do sistema de espaços livres da cidade.

As praças corporativas começaram a surgir com maior expressão nas maiores metrópoles brasileiras 
apenas nos anos de 1990. No entanto, alguns poucos projetos emblemáticos já haviam se instalado em São Paulo na década anterior, como o Brasilinvest Plaza (Figura 4), na avenida Brigadeiro Faria Lima, cujos espaços livres foram projetados por Ayako Nishikawa, e o Cetenco Plaza (Figura 5), na avenida Paulista, projetado por Luciano Fiaschi.

Atualmente, destacam-se as praças corporativas de "megaprojetos" empresariais localizados na Marginal Pinheiros, como os espaços livres do Centro Empresarial Nações Unidas (Figura 6), projetados pelo escritório DW/Santana, e do Bank Boston (Figura 7), projeto de Isabel Duprat.

Além destes projetos, no final da década de 1990 também começam a surgir alguns conceitos inéditos de espaços livres, como por exemplo o Brascan Century Plaza (Figura 8), de Benedito Abbud, empreendimento que conjuga atividades comerciais típicas de shopping centers com o espaço livre de praças corporativas, configurando open malls, verdadeiros shopping centers a céu aberto. Uma última tendência que tem se demonstrado gradualmente mais significativa é a configuração de condomínios corporativos fechados, compostos por diversas torres distribuídas ao redor de um espaço livre comum com tratamento bastante sofisticado, como é o caso do Millenium Office Park (Figura 9), empreendimento localizado na Vila Olímpia cujos espaços livres são projeto de DW/Santana.

\section{Notas}

(1) VILLAÇA, 1998.

(2) FRÚGOLI JÚNIOR, 2000.

\section{Bibliografia}

AKAMINE, Rogério. Desenho da paisagem úrbana: Avenidas Faria Lima, Paulista e Berrini. 1997. Dissertação (Mestrado em Arquitetura e Urbanismo) - Faculdade de Arquitetura e Urbanismo, Universidade de São Paulo, São Paulo, 1997.

BIDERMAN, Ciro; GROSTEIN, Marta Dora; MEYER, Regina Maria Prosperi. São Paulo Metrópole. São Paulo: Edusp e Imprensa Oficial, 2004.

FRÚGOLI JÚNIOR, Heitor. A centralidade em São Paulo: Trajetórias, conflitos e negociações na metrópole. São Paulo: Cortez Editora, 2000.

CAMPOS FILHO, Cândido Malta. Reinvente o seu bairro. São Paulo: Editora 34, 2002.

MACEDO, Silvio Soares. Espaços livres. Paisagem e Ambiente: Ensaios. São Paulo, n. 7, p. 15-56, 1995.

SOUZA, Maria Adélia Aparecida de. A identidade da metrópole. São Paulo: Hucitec, 1994.

VILLAÇA, Flávio. Espaço intra-urbano no Brasil. São Paulo: Nobel, 1998. 